\title{
Developing regional workplace health and hazard surveillance in the Americas
}

\author{
Bernard C. K. Choi, ${ }^{1}$ L. Maritza Tennassee, ${ }^{2}$ \\ and Gerry J. M. Eijkemans ${ }^{3}$
}

ABSTRACT An objective of the Workers' Health Program at the Pan American Health Organization (PAHO) is to strengthen surveillance in workers' health in the Region of the Americas in order to implement prevention and control strategies. To date, four phases of projects have been organized to develop multinational workplace health and hazard surveillance in the Region. Phase 1 was a workshop held in 1999 in Washington, D.C., for the purpose of developing a methodology for identifying and prioritizing the top three occupational sentinel health events to be incorporated into the surveillance systems in the Region. Three surveillance protocols were developed, one each for fatal occupational injuries, pesticide poisoning, ${ }^{4}$ and low back pain, which were identified in the workshop as the most important occupational health problems. Phase 2 comprised projects to disseminate the findings and recommendations of the Washington Workshop, including publications, pilot projects, software development, electronic communication, and meetings. Phase 3 was a sub-regional meeting in 2000 in Rosario, Argentina, to follow up on the progress in carrying out the recommendations of the Washington workshop and to create a Virtual Regional Center for Latin America that could coordinate the efforts of member countries. Currently phase 4 includes a number of projects to achieve the objectives of this Center, such as pilot projects, capacity building, editing a compact disk, analyzing legal systems and intervention strategies, software training, and developing an internet course on surveillance. By documenting the joint efforts made to initiate and develop Regional multinational surveillance of occupational injuries and diseases in the Americas, this paper aims to provide experience and guidance for others wishing to initiate and develop regional multinational surveillance for other diseases or in other regions.

Key words Workers' health, occupational health, hazard surveillance, health surveillance, occupational sentinel health event; prioritization.

1 Centre for Chronic Disease Prevention and Control, Health Canada, Ottawa, Canada; Department of Public Health Sciences, University of Toronto; and Department of Epidemiology and Community Medicine, University of Ottawa, Canada. Mailing address: Surveillance and Risk Assessment Division, Centre for Chronic Disease Prevention and Control, Population and Public Health Branch, Health Canada, Tunney's Pasture, PL\#1918C3, Ottawa, Canada K1A 0K9. Fax: (613) 954-8286. E-mail: Bernard_Choi@hc-sc.gc.ca

2 Workers' Health Program, Division of Health and Environment, Pan American Health Organization, Washington DC, U.S.A.

3 Occupational and Environmental Health, Programme on Health and Environment (OEH-PHE), World Health Organization, Geneva, Switzerland, and International Labour Organization, Geneva, Switzerland.
For several years, the Pan American Health Organization (PAHO) has been calling attention to the importance of improving the quality of surveillance data on workers' health in the Americas, in order to achieve better preven-

\footnotetext{
4 There is some overlap between fatal occupational injuries and pesticide poisonings, since the latter category includes fatal and non-fatal cases. However, this is not felt to be a problem given the fact that pesticide poisonings are also included under fatal occupational injuries.
}

tion and control of workplace health hazards and to improve workers' health and safety. At present, assessing the burden of occupational accidents and diseases in the Region is difficult due to a lack of reliable surveillance information, difficulties in the diagnosis of occupational diseases, and problems with the notification systems. To obtain more precise estimates of the burden of occupational injuries and diseases in the Region, it is necessary to continue to improve and standard- 
ize the collection, analysis, and interpretation of occupational surveillance data in the Americas.

Prior to 1999, a number of initiatives had been carried out in the countries of the Region. They included the development and testing in Venezuela of a workers' health surveillance software, SUAVIDERO (Sistema de Información en Salud Ocupacional para la Vigilancia y la Detección de Riesgos Ocupacionales), which was meant to improve the registration of occupational accidents and diseases. Another software, SAISO (South Australian Industrial Supplies Office), was developed in Chile for the identification of hazardous workplaces. In Central America, a notification and surveillance system, PLAGSALUD (Proyecto Aspectos Ocupacionales y Ambientales de la Exposición a Plaguicidas en el Istmo Centroamericano), was developed by PAHO to ascertain the number of injuries caused by the use of pesticides. PAHO also developed a surveillance system for ergonomic risks among oil industry workers in ECOPETROL (Empresa Colombiana de Petróleos), Colombia's major oil company. New workplace surveillance systems were established in Mexico and Argentina. In several countries in the Region, the Ministries of Health, social security institutes, and some private insurance companies began developing occupational health registry and surveillance systems.

Within the context described above, in 1999 PAHO initiated a series of projects to develop Regional multinational workplace health and hazard surveillance in the Americas. The objective of the projects was to systematically summarize local experiences in several countries in occupational health surveillance for promotion among other countries in the Region, in order to develop and strengthen capacity for Region-wide surveillance. A fundamental premise held by PAHO is that efforts in this field cannot be isolated from the activities of the Ministry of Health, Ministry of Labor, and social security institute within each country.

The first phase of the projects was a 3day workshop held in 1999 in Washing- ton, D.C., United States of America, for the purpose of addressing the major problems in the surveillance of workers' health and defining and prioritizing occupational sentinel health events. This was followed by the second phase, comprising a series of meetings and projects aimed at promoting the findings and recommendations of the Washington workshop among those responsible for workers' health in the countries of the Americas. The third phase was a 3-day meeting in 2000 in Rosario, Argentina, in which representatives of MERCOSUR (Mercado Común del Sur) countries-Argentina, Bolivia, Brazil, Chile, Uruguay, and Paraguay - evaluated the feasibility of implementing the sentinels programs. This meeting led to the creation of a Virtual Regional Center for Latin America for occupational epidemiological surveillance. Currently, the fourth phase consists of a number of projects to carry out the objectives of this Center.

This paper describes the methodology and results to date of the four phases of projects for developing Regional multinational workplace health and hazard surveillance in the Americas.

\section{Phase 1: The 1999 Washington workshop}

The objectives of the Washington workshop were to discuss and analyze the main problems found in the surveillance of workers' health in the Americas; to identify and prioritize occupational sentinel health events in workers' health which should be recommended for incorporation into the surveillance systems in the Region; and to develop the initial protocols and mechanisms for the implementation of the three top-priority occupational sentinel health events selected for workplace health and hazard surveillance in the Region. The methods and results of the Washington workshop are described in detail elsewhere (1-3) and are briefly summarized in this paper.

The 3-day workshop, entitled "Meeting on Surveillance in Workers' Health in the Americas", was organized by PAHO and held on July 7-9, 1999, at
PAHO Headquarters in Washington, D.C. PAHO invited 24 occupational health experts from 13 countries in the Region to participate. The number of participants from $\mathrm{PAHO}, \mathrm{WHO}$, and the countries was as follows: PAHO (2), WHO (1), Argentina (2), Brazil (1), Canada (1), Chile (2), Colombia (3), Costa Rica (1), Ecuador (2), Guyana (1), Mexico (2), Peru (2), USA (3), and Venezuela (1). There were 24 experts distributed as follows: government (13), universities (4), international health organizations (3), research institutes (2), PAHO (2), WHO (1), consulting firms (1), and industry (1). The first day was an update on the current situation in the Americas. This included a number of presentations on various aspects of workers' health surveillance in the Region and brief summaries of the surveillance activities in workers' health in various countries.

The second day was devoted to prioritizing sentinel health events. The 24 experts were divided into three small groups, each consisting of eight members. The small groups worked independently and simultaneously in discussing and analyzing the main problems for surveillance in workers' health in the Americas, and in developing a scoring system to prioritize health events from a list of 5 to 10 health problems considered to be of high priority for surveillance. In a subsequent plenary session, results of the small groups' activities were consolidated into a recommended list of three top-priority occupational sentinel health events for the Region.

The third day of the workshop was spent on developing a surveillance protocol. The same three small groups who met on the second day were asked to develop the initial protocols for the three top-priority occupational sentinel health events chosen on the second day, in order to implement their surveillance in the Region. Each expert group developed a protocol for one of the three occupational sentinel health events.

During the workshop, many of the participants suggested that occupational sentinel health events should be expanded to include not only health 
outcomes (e.g., diseases and injuries) (4), but also exposures (e.g., environmental hazard levels and biological monitoring) and interventions (e.g., prevention and control strategies). The rationale was that exposures (which carry a positive risk) and interventions (which carry a negative risk) can predict health outcomes and it is therefore important to include such occupational sentinel health events in workplace surveillance (5). The three small groups came up with a list of occupational sentinel health events ( 25 health outcomes, 18 occupational exposures, and 6 intervention strategies) (3). Through a systematic prioritization process, using scoring systems based on four criteria (magnitude, severity, costs, intervention/prevention possibilities) $(6,7)$, the three small groups each developed a list of 5-10 priority sentinel health events (Table 1). From the three lists, it was determined that the top three occupational sentinel health events were fatal occupational injuries, pesticide poisoning, and low back pain. The three small groups then proceeded to develop protocols for setting up surveillance systems for these three sentinel health events. The protocols included the objectives of the system, case definitions, organization and structure of the system, prevention strategies, stakeholders and their responsibilities, and a number of other relevant aspects for a surveillance system (3).

\section{Phase 2: Subsequent work following the Washington workshop}

The Washington workshop findings, including the three top priority occupational sentinel health events and the protocols for establishing their surveillance systems, were disseminated and promoted among several countries in the Region through various means:

- Publications. Proceedings of the workshop were published in 1999 (1). Two articles summarizing the experience of the PAHO workshop

TABLE 1. Occupational sentinel health events given the top 5 priority levels at the Washington Workshop, 1999

\begin{tabular}{|c|c|c|c|}
\hline \multirow{2}{*}{$\begin{array}{l}\text { Priority } \\
\text { level }\end{array}$} & \multicolumn{3}{|c|}{ Occupational sentinel health event ${ }^{\mathrm{a}}$} \\
\hline & Group 1 & Group 2 & Group 3 \\
\hline First & $\begin{array}{l}\text { Fatal occupational injury } \\
(\mathrm{H})\end{array}$ & Working at heights $(E)$ & Low back pain $(\mathrm{H})$ \\
\hline Second & $\begin{array}{l}\text { Pesticide exposure (E) } \\
\text { Protective equipment (I) }\end{array}$ & $\begin{array}{l}\text { Fatal occupational injury } \\
(\mathrm{H}) \\
\text { Pesticide exposure }(\mathrm{E})\end{array}$ & $\begin{array}{l}\text { Fatal occupational injury } \\
(\mathrm{H}) \\
\text { Pesticide poisoning }(\mathrm{H}) \\
\text { Heavy metal poisoning }(\mathrm{H})\end{array}$ \\
\hline Third & $\begin{array}{l}\text { Low back pain }(H) \\
\text { Noise-induced hearing } \\
\text { loss }(H)\end{array}$ & $\begin{array}{l}\text { Pesticide poisoning }(\mathrm{H}) \\
\text { Infection due to exposure } \\
\quad \text { to body fluids }(\mathrm{H}) \\
\text { Occupational cancer }(\mathrm{H}) \\
\text { Working with high } \\
\quad \text { frequency electricity }(\mathrm{E})\end{array}$ & Stress (E) \\
\hline Fourth & $\begin{array}{l}\text { Noise exposure }(E) \\
\text { Heavy metal poisoning }(H) \\
\text { Ergonomic risk factors }(E)\end{array}$ & $\begin{array}{l}\text { Chronic respiratory } \\
\text { illness }(\mathrm{H})\end{array}$ & Asthma $(\mathrm{H})$ \\
\hline Fifth & $\begin{array}{l}\text { Occupational infectious } \\
\text { disease }(\mathrm{H}) \\
\text { Regulatory activity (I) } \\
\text { Sanitary conditions (I) } \\
\text { Reproductive toxic } \\
\text { agents (E) }\end{array}$ & $\begin{array}{l}\text { Serious accidents }(E) \\
\text { Low back pain }(H) \\
\text { Noise induced hearing } \\
\text { loss }(H)\end{array}$ & $\begin{array}{l}\text { Noise induced hearing loss } \\
(\mathrm{H})\end{array}$ \\
\hline
\end{tabular}

a $\mathrm{H}$ : health outcomes; E: occupational exposures; I: intervention strategies.

were published in 2000 (2) and 2001 (3), respectively.

- Pilot projects. Two pilot projects sponsored by PAHO were conducted to test the conceptual framework developed at the Washington workshop: one pilot project in Peru through Social Security and Health (ESSalud, Seguro Social de Salud); the other in Chile through the Ministry of Health. The pilot projects tested the feasibility of implementing the sentinel health event surveillance protocols. For example, the pilot project in Peru, coordinated by PAHO Lima, was a small-scale test project, supported by three sentinel assistance centers, whose aim was to evaluate the surveillance of the three top-priority sentinel health events.

- Software development. The technical process of developing computer software was accelerated in various countries.

- Electronic communication. An Internet-based discussion network was developed for monitoring the progress of the pilot projects and for exchanging information. This network (in English, Spanish, and Portuguese) is located on the existing webpage of Workers' Health (http://www.cepis.org.pe) in the Pan American Center for Sanitary Engineering and Environmental Sciences (CEPIS). The latter, established in 1968 and located in Lima, Peru, is PAHO's specialized center for environmental technology.

- Meetings. PAHO's Regional Plan for Workers' Health, which incorporated findings from the Washington workshop, was presented at the meeting of the Ministers of Health of the Americas in September 1999. An agreement was reached on the importance of strengthening workers' health and its surveillance systems throughout the Region. A guideline for Regional policy was approved to support the development of national projects in workers' health surveil- 
lance. Several other meetings were organized to coordinate actions among the Ministries of Health and Labor, social security institutes, and representatives of workers and employers. During dissemination of the workshop findings, it was stressed that the three top-priority occupational sentinel health events were selected on the basis of a ranking exercise and negotiation among occupational health experts at the Washington workshop. It was recommended that the countries begin working on the three sentinel health events, with the possibility of including others if considered appropriate. The sentinel health events proposed by PAHO do not necessarily reflect the priorities for each country. In addition, the surveillance protocols developed at the Washington workshop should only be used as a general guideline and should be modified to suit local situations. The countries could use the protocols as models on how to approach the first phase of conceptualizing a surveillance system. Biennial meetings were planned in the Region to follow up on the progress of strengthening surveillance systems in various countries, with the first meeting planned for 2000 in Rosario, Argentina.

\section{Phase 3: The 2000 Rosario Meeting}

This three-day meeting, entitled "First Meeting on Occupational Epidemiological Surveillance for Member Countries of MERCOSUR and Associates", was held in Rosario, Argentina, from October 30 to November 1, 2000. Participants included representatives of various ministries, universities, and governmental and non-governmental organizations in Argentina, Bolivia, Brazil, Chile, Paraguay, and Uruguay, and $\mathrm{PAHO}$ representatives from Washington, D.C. The status of occupational health surveillance in each of the countries in the Region of the Americas was presented, with particular emphasis on weaknesses and strengths. This was followed by comments from each country representative on the progress attained in this area after the 1999 Washington workshop.

As a result of the discussion and debate during these three days, a decision was made to establish the "Virtual Regional Center for Latin America." The Center's management is assumed by rotation for a period of 2 years, starting with Argentina, where the Center's headquarters are located in Rosario. Members of the management are from the School of Medical Sciences, the National University of Rosario, and the Department of Epidemiology of the Ministry of Public Health of the Municipality of Rosario. The Center has several main objectives:

- To promote and implement, in the Region, projects on workplace sentinel health surveillance in order to develop prevention and control strategies to improve the quality of workers' life.

- To collaborate with member countries in the dissemination of information and capacity-building in workplace sentinel health surveillance. An example is the editing and publishing of a compact disk (CD) for dissemination among Member States. The content of the CD includes the current situation of occupational health surveillance in each country, documentation and analysis of the legislation in occupational health and safety, a compilation of research projects relating to occupational health in the Region, an inventory of programs in occupational health surveillance, and systems in both the private and public sectors to prevent occupational injuries and diseases.

- To analyze and assess the legal systems and intervention strategies, such as risk control and health and safety promotion in the workplace, and the impact of such legal systems and intervention strategies on workers' health.

- To provide training and advisory services on software for occupational health surveillance, such as SUAVIDERO, SIVEO (Sistema de Vigilancia Epidemiológica Ocupa- cional, belonging to ECOPETROL), and CTERA (Confederación de Trabajadores de la Educación de la República Argentina).

- To develop and deliver regional training programs in occupational epidemiology and surveillance via Internet or teleconferences.

The Center is virtual in nature, in that it conducts its activities and provides its services through the Internet. Occupational health experts associated with the Center offer support to those organizations and institutions in Member Countries that are involved in the projects or that request services.

\section{Phase 4: Subsequent work after the Rosario Meeting}

A meeting was held in Rio de Janeiro, Brazil, in January 2001 to discuss the progress on the editing of the Center's CD (in accordance with the Center's second objective). The content and bibliography of the CD is constantly being updated, with a view to releasing the update every two years. A meeting was also held in 2001 in Bolivia to further discuss projects and collaboration on workplace sentinel health surveillance in the Region (first and second objectives). A regional meeting in Chile is being planned to study the impact of workplace health insurance systems in the Region, both non-profit and for-profit, over the last 10 years (third objective). The Center provides ongoing consultation services and training to the Member States on the use of software for occupational health surveillance and other related topics (fourth objective). Currently an Internet course is being developed on workplace sentinel health surveillance that can be administered through video teleconferences, by satellite, or in the classroom (fifth objective). Besides basic principles of occupational epidemiology and surveillance, the course will focus on the practical aspects, including training on the use of computer software such as Epi Info (creating databases and basic statistical analysis), SUAVIDERO (basic concepts 
and operation), and other computer tools (SAISO, SIVEO, and CTERA).

\section{DISCUSSION}

Public health surveillance is traditionally the mandate of the government of a country $(8,9)$. It has become evident in recent years, however, that surveillance may need to be performed in a concerted way among countries at a regional or even global level to generate comparable data (10). Occupational diseases that are infectious may follow workers across borders. One country can improve its prevention and control efforts by knowing about the disease burden and the effectiveness of prevention and control efforts in other countries. Developing countries may foresee the forthcoming wave of new types of occupational injuries and diseases due to the new occupational exposures associated with upgrading technologies to match those of the developed countries. It is also recognized that there is a need to create data standards for comparison among countries at similar stages of industrial development. Standard notification forms and coding manuals can allow countries to ensure data comparability. Standard formats and tables for annual reports can also permit international comparisons. When countries report occupational health statistics in a standard fashion, early warnings can be drawn from the experiences of other countries. For example, new occupational problems reported in Brazil may lead Venezuela to watch out for similar problems. Finally, there is a strategic value to initiating work on surveillance systems where occupational health in general is weak. The jointly developed surveillance system can be useful in directly applying the successful experiences of some Member States to others and in triggering action in occupational health in general.

Achieving international concerted efforts for occupational health surveillance, however, is not an easy task, especially when the objective is to develop multinational surveillance in a region. This paper documents the first successes experienced over several years by PAHO and its Member States in occupational sentinel health surveillance in the Americas. This experience is valuable to others who want to develop and launch multinational surveillance initiatives in other disease areas, such as non-communicable diseases, or in other regions, such as Southeast Asia. Characteristics of this process are summarized below.

First, it is important to have the leadership of an international public health agency to bring about and catalyze multinational efforts. In this case, PAHO has the mandate to act in this capacity to summon the meetings, coordinate surveillance efforts, follow up on pilot projects in some countries and promote them in other countries when successful, and make recommendations among its 38 Member States. PAHO can also provide some seed funding to initiate pilot projects. For occupational surveillance on a global scale, the International Labour Organisation (ILO) has provided assistance in areas such as the transfer of technology, training, and technical assistance activities, from developed countries to countries in development $(2,11)$.

Second, an expert consensus workshop based on a systematic process is an efficient and reliable method for achieving multinational agreement (3). In the 1999 Washington workshop, which lasted more than a total of 72 person-days, discussions focused on problems in the surveillance of workers' health, and methodologies were developed to prioritize and select the top three occupational sentinel health events, as well as the initial protocols for establishing surveillance systems for them (1-3). The expert consensus approach yielded fruitful results that would not have been possible if a single expert had worked for 72 days. The major benefit arises from the integration of knowledge and expertise from a multidisciplinary and multinational team of experts.

Third, prioritization is important because resources are scarce. In occupa- tional health surveillance in the Americas, the three key areas identified are fatal occupational injuries, pesticide poisoning, and low back pain. In other health domains, or in other administrative regions, the key areas may be different.

Fourth, the multinational surveillance system must be developed in stages, from simple to complex. The surveillance system should start with a simple basic format and configuration and move to a higher level of sophistication over time (11). It is easier for various countries to agree, at least initially, on a simple basic format than on a complex format. After a period of collaboration and pilot projects, more sophisticated systems could be developed. For example, at a more complex level, there is a need to develop multinational common reporting standards (3), minimum datasets, strategies to reduce and prevent bias (13-15), including the healthy worker effect (16, $17)$, code of practice on recording and notification of occupational sentinel health events (12), standard notification forms and questionnaires with standard questions (11), standard coding schemes (11), common data dictionaries, standard data analysis protocols, minimum statistical indicators $(18,19)$, automated data analysis systems with built-in capability to provide early warnings $(3,5)$, and standard reports with standard tables and diagrams (11).

Fifth, the process should take advantage of modern technology. Examples include an Internet-based discussion site for information exchange, customized and highly specialized computer software for data storage and analysis, SIVEO, compact disks for information dissemination, and Internet, satellite and video teleconferences for meetings and training courses.

It is hoped that the experience gained from this series of joint projects to develop Regional multinational workplace health and hazard surveillance in the Americas will be helpful to those who are involved in the design and practice of surveillance systems in workers' health. 


\section{REFERENCES}

1. Pan American Health Organization. Proceedings of the Regional Meeting on Surveillance in Workers' Health in the Americas, July 7-9 1999. Washington, D.C.: Pan American Health Organization; 1999.

2. Choi BCK. Development of indicators for occupational health and safety surveillance: the Thai and Pan American Health Organization experiences. Asian-Pacific Newslett Occup Health Safety 2000;7:14-15.

3. Choi BCK, Eijkemans GJM, Tennassee LM. Prioritization of occupational sentinel health events for workplace health and hazard surveillance: The Pan American Health Organization experience. J Occup Environ Med 2001;43:147-157.

4. Mullan RJ, Murthy LI. Occupational sentinel health events: an updated list for physician recognition and public health surveillance. Am J Ind Med 1991;19:775-799.

5. Choi BCK. Perspectives on epidemiologic surveillance in the 21st century. Chronic Dis Canada 1998;19:145-151. http://www.hc-sc. gc.ca/hpb/lcdc/publicat/cdic/cdic194/cd19 4b_e.html

6. Centers for Disease Control and Prevention. Guidelines for evaluating surveillance sys- tems. MMWR 1988;37(S-5):1-18. http://www. cdc.gov/epo/mmwr/preview/mmwrhtml/ 00001769.htm

7. Klaucke DN. Evaluating public health surveillance systems. In: Halperin W, Baker EL Jr., eds. Public health surveillance. New York: Van Nostrand Reinhold; 1992. Pp.26-41.

8. Halperin W, Baker EL Jr. Public health surveillance. New York: Van Nostrand Reinhold, 1992.

9. Teutsch SM, Churchill RE. Principles and practice of public health surveillance. New York: Oxford University Press; 1994.

10. Choi BCK, Bonita R, McQueen DV. The need for global risk factor surveillance. J Epidemiol Comm Health 2001;55:370. http://www.jech. com

11. Choi BCK. Recording, notification, compilation, and classification of statistics of occupational accidents and diseases: the Thai experience. J Occup Environ Med 1996;38:1151-1160.

12. International Labour Office. Code of practice on recording and notification of occupational accidents and diseases. Geneva: International Labour Office; 1994.

13. Sackett DL. Bias in analytic research. J Chron Dis 1979;32:51-63.
14. Choi BCK, Noseworthy AL. Classification, direction, and prevention of bias in epidemiologic research. J Occup Med 1992;34:265-271.

15. Choi BCK, Pak AWP. Bias, overview. In: Armitage P, Colton T, eds. Encyclopedia of biostatistics. Chichester, Sussex, UK: John Wiley \& Sons Ltd.; 1998. Pp. 331-338.

16. Choi BCK. Definition, sources, magnitude, effect modifiers, and strategies of reduction of the healthy worker effect. J Occup Med 1992; 34:979-988.

17. Choi BCK. A technique to re-assess epidemiologic evidence in light of the healthy worker effect: the case of firefighting and heart disease. J Occup Environ Med 2000;42:1021-1034.

18. International Labour Office. Yearbook of labour statistics, 1994. 53rd Issue. Geneva: International Labour Office; 1994

19. International Labour Office. Current international recommendations on labour statistics. Geneva: International Labour Office; 1988.

Manuscript received 18 September 2001 and accepted for publication on 21 September 2001

RESUMEN Uno de los objetivos del Programa de Salud de los Trabajadores en la Organización Panamericana de la Salud (OPS) es fortalecer la vigilancia de la salud ocupacional en la Región de las Américas con objeto de implantar estrategias de prevención y control. Hasta la fecha se ha organizado un proyecto en cuatro fases para desarrollar la vigilancia multinacional de los problemas de salud ocupacionales en la Región. En la primera fase se llevó a cabo un taller en Washington, D.C., en 1999 con el fin de crear una metodología que permitiera identificar por orden de prioridad los tres problemas ocupacionales más importantes, con objeto de incorporarlos en los sistemas de vigilancia de la Región. Se crearon tres protocolos de vigilancia, uno para los accidentes ocupacionales mortales, otro para los envenenamientos por plaguicidas y un tercero para el dolor lumbar, que fueron los problemas de salud ocupacionales más importantes, según se determinó en el taller. La segunda fase se compuso de proyectos para diseminar los resultados y las recomendaciones del taller de Washington, incluidas sus publicaciones, proyectos piloto, programas para computadora, comunicaciones electrónicas y reuniones. La tercera fase consistió en una reunión subregional en 2000 en Rosario, Argentina, para ver cuánto se había avanzado en el cumplimiento de las recomendaciones del taller de Washington y para crear un Centro Regional Virtual para América Latina que pudiera coordinar las inciativas de los Estados Miembros. Y en la actualidad, la cuarta fase abarca una serie de proyectos encaminados a alcanzar los objetivos de este Centro, tales como proyectos piloto, mejoramiento de la capacidad, edición de un disco compacto, análisis de los sistemas jurídicos y de las estrategias de intervención, adiestramiento en el uso de programas de computadora y desarrollo de un curso internético de vigilancia. Mediante la documentación de las iniciativas conjuntas encaminadas a crear e impulsar la vigilancia multinacional de los accidentes y problemas de salud ocupacionales en la Región, el presente trabajo busca poner experiencias y orientación al alcance de quienes deseen crear y fomentar la vigilancia multinacional de otros problemas de salud en otras regiones. 